\title{
Efeito dos óleos essenciais sobre a antracnose in vitro e em frutos de mamoeiro
}

\author{
ANDRADE, W.P.'; VIEIRA, G.H.C. ${ }^{1}$ \\ -Universidade Estadual de Mato Grosso do Sul, Rodovia MS 306 Km 06, Unidade Universitária de Cassilândia, \\ Cep 79540-000. *Autor para correspondência: gcv@uems.br
}

RESUMO: As doenças pós-colheita do mamão são as principais responsáveis pelas perdas que ocorrem durante esse processo. A antracnose é uma doença causada pelo fungo Colletotrichum gloeosporioides. Esse patógeno tem a capacidade de se estabelecer no fruto imaturo, permanecendo em estado latente até que as condições se tornem favoráveis ao seu desenvolvimento. O presente estudo teve como objetivo determinar o efeito fungistático dos óleos essenciais sobre o fungo C.gloeosporioides. Os experimentos foram realizados no laboratório de Fitossanidade da Universidade Estadual de Mato Grosso do Sul, Unidade Universitária de Cassilândia, foram três etapas, quais sejam: I efeito dos óleos essenciais sobre a germinação de conídios, II- ação in vitro dos óleos sobre micélios fúngicos e III- efeito dos óleos essenciais sobre o fungo em frutos do mamoeiro. Para as três fases o delineamento experimental utilizado foi inteiramente casualizado, em esquema fatorial $6 \times 5$, (óleos essenciais de alecrim, menta, capim-limão, anis, árvore-chá e canela) e cinco concentrações $(0 \mu \mathrm{L}, 10 \mu \mathrm{L}$, $30 \mu \mathrm{L}, 50 \mu \mathrm{L}, 100 \mu \mathrm{L}$ ), com 5 repetições. A germinação de conídios foi afetada drasticamente pelos óleos de menta e árvore-chá. O efeito fungitóxico do óleo de menta foi confirmado nos experimentos subsequentes, nos quais essa substância na concentração de $100 \mu \mathrm{L}$ inibiu completamente o crescimento micelial invivo e in vitro do fungo C. gloeosporioides. Os óleos de alecrim e árvore-chá também afetam o crescimento micelial in vivo e in vitro desse fungo, embora em menor intensidade.

Palavras-chave: controle alternativo, fruticultura, doenças pós-colheita.

\begin{abstract}
Effect of essential oils on in vitro anthracnose and in fruits of the papaya plant. Post-harvest papaya diseases are primarily responsible for the losses suffered during this process. Anthracnose is a disease caused by the Colletotrichum gloeosporioides fungus. This pathogen has the ability to settle in the immature fruit, remaining dormant until conditions become favorable for its development. The purpose of this study was to determine the fungicidal effect of essential oils on the C. gloeosporioides fungus. The experiments were undertaken in the Plant Health laboratory of the State University of Mato Grosso do Sul, at the University Unit of Cassilandia, where an evaluation was performed in three stages, namely: I) the effect of essential oils on spore germination, II) the in vitro action of oils on mycelium fungi, and III) the effect of essential oils on the fungus in papaya fruit. For the three phases, the experimental design was completely randomized in a $6 \times 5$ factorial arrangement (essential oils of rosemary, mint, lemongrass, anise, tea tree, and cinnamon) and five concentrations ( $0 \mathrm{uL}, 10 \mathrm{uL}, 30 \mathrm{uL}, 50$ $\mathrm{uL}, 100 \mathrm{uL}$ ) with five replications. The spore germination was drastically affected by the mint and tea tree oils. The fungitoxic effect of peppermint oil was confirmed in subsequent experiments in which this substance at a concentration of $100 \mathrm{uL}$ completely inhibited the mycelial in vivo and in vitro growth of the $C$. gloeosporioides fungus. The rosemary and tea tree oils also affect the mycelial in vivo and in vitro growth of this fungus, albeit to a lesser degree.
\end{abstract}

Keywords: alternative control, fruticulture, post-harvest diseases.

\section{INTRODUÇÃO}

A crescente demanda, pelos consumidores, por produtos de boa aparência e qualidade, aliada ao menor uso de agrotóxicos, tem exigido grande atenção por parte dos produtores, com relação aos cuidados fitossanitários nas fases de produção e pós-colheita dos frutos, que limitam a sua inserção 
no mercado pela perda da sua qualidade (Cerdeño, 2006).

Os fungos são os principais responsáveis pelo surgimento de doenças que resultam nas perdas observadas no período pós-colheita (Ventura \& Costa, 2003). O controle desses patógenos é realizado com o uso de fungicidas, que resultam em frutos com resíduos nocivos à saúde, tornando a população vulnerável às infecções e até mesmo ao desenvolvimento de doenças (Rozwalka, 2003).

Nehmi et al. (2002) o mamoeiro (Carica papaya L.) é uma das fruteiras mais cultivadas nos países de clima tropical, o Brasil é o maior produtor e exportador mundial, com uma produção de 1,7 milhões de toneladas/ano, que corresponde a $35,4 \%$ do volume mundial.

A antracnose é a principal doença póscolheita a afetar o mamoeiro. Essa doença é causada pelo fungo Colletotrichum gloeosporioides, que tem a capacidade de se estabelecer no fruto imaturo e permanecer em estado latente, sem o aparecimento de sintomas, até que haja condições para que o processo de infecção ocorra (Nery-silva et al., 2007)

Visando à segurança alimentar e à proteção ambiental, pela extinção e/ou substituição do uso de produtos químicos por produtos alternativos, diversas pesquisas têm sido realizadas com extratos vegetais com o intuito de comprovar a eficácia dessas substâncias no controle de fitopatógenos causadores de doenças de pós-colheita no mamoeiro (Guiraldo et al., 2004).

Dentre as principais substâncias alternativas usadas no controle fitossanitário de doenças podemse destacar os óleos essenciais, cujas propriedades antimicrobianas já são significativamente reconhecidas (Oliveira et al., 2006).

O presente trabalho teve como objetivo determinar o potencial antimicrobiano de diferentes óleos essenciais sobre o fungo C.gloeosporioides causador da antracnose em mamoeiro.

\section{MATERIAL E MÉTODOS}

Os experimentos foram conduzidos no período de janeiro a julho de 2014 no laboratório de Fitossanidade da Universidade Estadual de Mato Grosso do Sul, Unidade Universitária de Cassilândia. Foram usados os óleos essenciais de anis (Pimpinella anisum), capim-limão (Cymbopogon citratus), alecrim (Rosmarinus officinalis), canela (Cinnamomum zeylanicum), árvore-chá (Melaleuca alternifolia) e menta (Mentha piperita), adquiridos de forma comercial, provenientes da Farmácia de Ervas Ribeirão Preto - SP.

\section{Ensaio I: Efeito fungitóxico dos óleos}

\section{essenciais em conídios}

A atividade antifúngica dos óleos essenciais em diferentes concentrações sobre a germinação de conídios foi determinada mediante à análise microscópica dessas estruturas desenvolvidas em meio de cultura B.D.A. acrescido de óleos essenciais em diferentes concentrações. A suspensão aquosa de conídios foi preparada por meio da adição e filtragem de micélios fúngicos de $C$. gloeosporioides, utilizando-se água esterilizada deionizada e gaze. A concentração de esporos dessa suspensão foi determinada com auxílio de hemocitômetro, ajustada para a $2 \times 10^{6}$ conídios $/ \mathrm{ml}$. Os óleos essenciais foram adicionados ao meio de cultura B.D.A. com o auxílio de uma micropipeta de volume variável. Essas substâncias foram adicionadas ao meio B.D.A., após a autoclavagem desse meio e enquanto ainda se encontravam em estado fundente. Usouse um agitador magnético com aquecimento para homogeneizar os óleos essenciais ao meio de cultura, sendo em seguida vertidos em placas de Petri com o diâmetro de $90 \mathrm{~mm}$. As amostras de $5000 \mu \mathrm{L}$ da suspensão conidial foram depositadas sobre as placas de petri vertidas, sendo incubadas em B.O.D. à $25^{\circ} \mathrm{C} \pm 2^{\circ} \mathrm{C}$, com fotoperíodo de 12 horas. A avaliação foi realizada determinando-se a porcentagem de germinação de 100 conídios, 14 horas após o início da incubação, contando-se o número de esporos germinados e não germinados ao microscópio óptico em três diferentes pontos da placa de Petri, no aumento de 40x (Silva \& Bastos, 2007). Foram considerados como esporos germinados aqueles que apresentaram tubo germinativo, que apresentarem tamanho igual ou superior aos conídios.

Ensaio II: Atividade antimicrobiana in vitro A atividade antimicrobiana in vitro dos óleos essenciais sobre C. gloesporioides foi determinada por meio do crescimento micelial do fungo em meio de cultura acrescido das referidas substâncias em diferentes concentrações. Os óleos essenciais em diferentes concentrações foram adicionados ao meio de cultura ainda fundente, sendo usado um agitador magnético com aquecimento para homogeneizar a solução, sendo essa mistura vertida em placas de Petri com $90 \mathrm{~mm}$ de diâmetro (Leme et al., 2007). Cada tratamento recebeu um disco de 5 $\mathrm{mm}$ de diâmetro contendo micélio e esporos de $C$. gloeosporioides provenientes da colônia pura com idade de 7 dias, mantidos em B.O.D. por oito dias a temperatura de $25^{\circ} \mathrm{C} \pm 2^{\circ} \mathrm{C}$, com fotoperíodo de 12 horas luz.

A avaliação foi realizada 96 horas após a inoculação do fungo através de medições do diâmetro das colônias (média de duas medidas diametralmente opostas) (Leite et al., 2009).

Rev. Bras. PI. Med., Campinas, v.18, n.1, supl. I, p.367-372, 2016. 
Ensaio III: Avaliação do controle alternativo

Os frutos de mamoeiro cultivar Golden foram adquiridos nos supermercados de Cassilândia - MS. Esses frutos foram selecionados e foram utilizados frutos que apresentavam mais de 50\% com a coloração amarela da casca, onde a uma condição fisiológica do fruto para o desenvolvimento das hifas do fungo (Gomes, 2008), passaram por um processo de assepsia, foram lavados com detergente neutro e submetidos a um tratamento hidrotérmico, sendo mantidos a $49^{\circ} \mathrm{C}$ por 20 minutos e em seguida resfriados a $8^{\circ} \mathrm{C}$ por 20 minutos e embalados em sacos plásticos (Akamine \& Arisumi, 1953).

Nos testes com os frutos foram realizados os mesmos tratamentos apresentados nos experimentos I e II. Realizada a assepsia, a parte da superfície dos frutos, com cerca de $10 \mathrm{~mm}$ de diâmetro foi levemente escoriada com o auxílio de bisturi, sendo então aplicadas as substâncias dos tratamentos utilizando uma micropipeta, permanecendo por $24 \mathrm{~h}$ em ambiente asséptico para a secagem completa do material. Paralelo aos testes estabeleceu um grupo controle no qual os frutos receberam apenas água deionizada. Após esse período, os frutos, receberam um disco de B.D.A. de $5 \mathrm{~mm}$ de diâmetro com micélio fúngico. Esses discos foram retirados da cultura pura com idade de 7 dias. Em seguida, os frutos foram recobertos com sacos plásticos e incubados em B.O.D., a $25^{\circ} \mathrm{C} \pm 2^{\circ} \mathrm{C}$.

A avaliação foi realizada através de medições do diâmetro da lesão in vivo (média de duas medidas diametralmente opostas), 96 horas após a inoculação nos frutos (Leite et al., 2009).

\section{Análise Estática dos ensaios I, II e III}

O delineamento experimental utilizado foi o Delineamento Inteiramente Casualizado, em esquema fatorial $6 \times 5$, (óleos essenciais de alecrim, menta, capim-limão, anis, árvore-chá, canela) e cinco concentrações $(0 \mu \mathrm{L}, 10 \mu \mathrm{L}, 30 \mu \mathrm{L}, 50 \mu \mathrm{L}, 100$ $\mu \mathrm{L}$ ), com 5 repetições. As médias foram comparadas pelo teste de Tukey $(P<0,05)$, utilizando o software Sisvar (Ferreira, 2011).

\section{RESULTADOS \\ Efeito fungitóxico dos óleos essenciais na germinação de conídios}

Os resultados mostram que houve diferença estatística, entre os tratamentos na inibição na germinação dos conídios de C. gloeosporioides, embora a eficiência inibitória tenha oscilado em relação às concentrações, a taxa de germinação dos conídios decresceu com o aumento das concentrações testadas, diferindo significativamente do controle.

Os óleos essenciais com a concentração de $10 \mu \mathrm{L}$ de capim-limão e anis inibiram 38,6\% e 39,4\%, apresentaram os maiores efeitos negativos sobre a germinação. Os óleos essenciais de capim-limão $28,4 \%$ e alecrim $31,2 \%$ apresentaram os maiores efeitos sobre a germinação na concentração de $30 \mu \mathrm{L}$. O óleo essencial de árvore-chá com $14,0 \%$, sobre a germinação na concentração de $50 \mu \mathrm{L}, \mathrm{O}$ óleo essencial de menta com $9,4 \%$ apresentou o maior efeito sobre os conídios na concentração de $100 \mu \mathrm{L}$ entre todos os tratamentos.

\section{Atividade antimicrobiana in vitro}

Os valores do crescimento micelial no período de 96 horas, entre os tratamentos, o óleo essencial (10 $\mu \mathrm{L})$, de capim-limão $25,8 \mathrm{~mm}$, teve o maior efeito fungitóxico.

Os óleos essenciais (30 $\mu \mathrm{L})$, capim-limão $25,8 \mathrm{~mm}$, canela $27,0 \mathrm{~mm}$ e anis $31,2 \mathrm{~mm}$ os maiores efeitos fungitóxicos. Os óleos essenciais $(50 \mu \mathrm{L})$ de árvore-chá $18,67 \mathrm{~mm}$, alecrim 23,2

TABELA 1. Germinação in vitro de conídios de Colletotrichum gloeosporioides submetidos a diferentes óleos essenciais em diferentes concentrações em \%.

\begin{tabular}{ccccccc}
\hline \multicolumn{7}{c}{ Germinação (\%) } \\
\hline Doses & Alecrim & Menta & Capim- Limão & Anis & Árvore- Chá & Canela \\
\hline $0 \mu \mathrm{L}$ & $55,8 \mathrm{aD}$ & $55,8 \mathrm{aE}$ & $55,8 \mathrm{aC}$ & $55,8 \mathrm{aC}$ & $55,8 \mathrm{aD}$ & $55,8 \mathrm{aB}$ \\
$10 \mu \mathrm{L}$ & $42,4 \mathrm{bC}$ & $46,2 \mathrm{cD}$ & $38,6 \mathrm{aB}$ & $39,4 \mathrm{aB}$ & $47,6 \mathrm{cC}$ & $53,2 \mathrm{~dB}$ \\
$30 \mu \mathrm{L}$ & $31,2 \mathrm{abB}$ & $43,0 \mathrm{cC}$ & $28,4 \mathrm{aA}$ & $31,4 \mathrm{bA}$ & $44,4 \mathrm{cB}$ & $48,4 \mathrm{dA}$ \\
$50 \mu \mathrm{L}$ & $25,6 \mathrm{bA}$ & $38,6 \mathrm{~dB}$ & $28,2 \mathrm{bcA}$ & $31,0 \mathrm{cA}$ & $14,0 \mathrm{aA}$ & $48,0 \mathrm{eA}$ \\
$100 \mu \mathrm{L}$ & $24,4 \mathrm{cA}$ & $9,4 \mathrm{aA}$ & $28,0 \mathrm{dA}$ & $31,0 \mathrm{eA}$ & $13,6 \mathrm{bA}$ & $48,0 \mathrm{fA}$ \\
\hline $\mathrm{F}($ Trat $)=$ & $350,28^{* *}$ & & & & & \\
\hline C.V. $(\%)=$ & 4,04 &
\end{tabular}

Letras iguais minúscula na linha e maiscula na coluna não diferem entre si pelo teste de Tukey a $5 \%$ de probabilidade*, Teste $\mathrm{F}$ significativo ao nível de $5 \%$, C.V. Coeficiente de Variação.

Rev. Bras. PI. Med., Campinas, v.18, n.1, supl. I, p.367-372, 2016. 
$\mathrm{mm}$ e capim-limão $25,0 \mathrm{~mm}$ apresentaram efeitos fungitóxicos. $\mathrm{O}$ óleo essencial de menta $(100 \mu \mathrm{L})$ inibiu o crescimento micelial. por completo $(0,0 \mathrm{~mm})$.

A variação do crescimento micelial para as diferentes concentrações de $0,10,30,50$ e $100 \mu \mathrm{L}$ dos óleos essenciais, o alecrim, menta, anis, árvorechá e canela com o aumento da concentração a uma diminuição no crescimento micelial do fungo diferindo significativamente comparado com o controle. O óleo essencial de capim-limão nas concentrações de 10 a $100 \mu \mathrm{L}$ não diferiram entre $\mathrm{si}$, apresentaram efeito fungistático, diferindo do controle.

vivo.

\section{Avaliação do controle da antracnose in}

Após a inoculação, no período de 96 horas, comparando o efeito dos tratamentos sobre o tamanho da lesão na dose $10 \mu \mathrm{L}$, observa-se que o óleo essencial de capim-limão $25,8 \mathrm{~mm}$ teve o maior efeito fungitóxico no desenvolvimento das lesões.

Os melhores efeitos fungitóxicos foram os óleos essenciais ( $30 \mu \mathrm{L}$ ), de capim-limão $25,0 \mathrm{~mm}$, canela $27,0 \mathrm{~mm}$ e anis $31,2 \mathrm{~mm}$.

Os óleos essenciais $(50 \mu \mathrm{L})$ de árvore-chá $18,6 \mathrm{~mm}$, alecrim $23,2 \mathrm{~mm}$ e capim-limão $25,0 \mathrm{~mm}$, obtiveram os menores desenvolvimentos fúngicos.

A concentração avaliada de $100 \mu \mathrm{L}$, o óleo essencial de menta inibiu o crescimento micelial por completo $(0,00 \mathrm{~mm})$ apresentando uma característica fungicida.

O desenvolvimento das lesões para as diferentes concentrações de 0,10,30, 50 e $100 \mu \mathrm{L}$ dos óleos essenciais, o alecrim, menta, anis, árvorechá e canela com o aumento da concentração a uma diminuição das lesões diferindo significativamente

TABELA 2. Crescimento micelial in vitro do fungo Colletotrichum gloeosporioides expostos a diferentes concentrações óleos essenciais

\begin{tabular}{ccccccc}
\hline \multirow{7}{*}{ Doses } & \multicolumn{7}{c}{ Diâmetro médio após 96h da inoculação (mm) } \\
\cline { 2 - 7 } & Alecrim & Menta & Capim-limão & Anis & Árvore- Chá & Canela \\
\cline { 2 - 7 } & $77,0 \mathrm{aD} D^{*}$ & $77,0 \mathrm{aD}$ & $77,0 \mathrm{aB}$ & $77,0 \mathrm{aC}$ & $77,0 \mathrm{aC}$ & $77,0 \mathrm{aC}$ \\
$10 \mu \mathrm{L}$ & $44,4 \mathrm{cC}$ & $67,2 \mathrm{eC}$ & $25,8 \mathrm{aA}$ & $33,0 \mathrm{bB}$ & $53,7 \mathrm{~dB}$ & $33,4 \mathrm{bB}$ \\
$30 \mu \mathrm{L}$ & $34,3 \mathrm{bB}$ & $62,0 \mathrm{dBC}$ & $25,0 \mathrm{aA}$ & $31,2 \mathrm{abB}$ & $48,2 \mathrm{cB}$ & $27,0 \mathrm{aAB}$ \\
$50 \mu \mathrm{L}$ & $23,2 \mathrm{abA}$ & $59,1 \mathrm{~dB}$ & $25,0 \mathrm{abcA}$ & $31,2 \mathrm{cB}$ & $18,6 \mathrm{aA}$ & $27,0 \mathrm{bcAB}$ \\
$100 \mu \mathrm{L}$ & $16,6 \mathrm{bcA}$ & $0,0 \mathrm{aA}$ & $25,0 \mathrm{dA}$ & $23,3 \mathrm{cdA}$ & $14,7 \mathrm{bA}$ & $25,9 \mathrm{dA}$ \\
\hline $\mathrm{F}($ Trat $)=$ & $67,03^{* *}$ & & & & & \\
\hline $\mathrm{CV}(\%)=$ & 9,19 &
\end{tabular}

Letras iguais minúscula na linha e maiscula na coluna não diferem entre si pelo teste de Tukey a 5\% de probabilidade*, Teste F significativo ao nível de $5 \%{ }^{* *}$, C.V. Coeficiente de Variação.

TABELA 3. Desenvolvimento da lesão in vivo do fungo Colletotrichum gloeosporioides expostos a diferentes concentrações de óleos essenciais

Diâmetro médio das lesões após 96h da inoculação (mm)

\begin{tabular}{lcccccc}
\cline { 2 - 6 } Doses & \multicolumn{7}{c}{ Tratamentos } \\
\cline { 2 - 7 } & Alecrim & Menta & Capim- Limão & Anis & Árvore- Chá & Canela \\
\hline $0 \mu \mathrm{L}$ & $77,00 \mathrm{aD}$ & $77,00 \mathrm{aD}$ & $77,00 \mathrm{aB}$ & $77,00 \mathrm{aC}$ & $77,00 \mathrm{aC}$ & $77,00 \mathrm{aC}$ \\
$10 \mu \mathrm{L}$ & $44,40 \mathrm{cC}$ & $67,20 \mathrm{eC}$ & $25,80 \mathrm{aA}$ & $33,00 \mathrm{bB}$ & $53,75 \mathrm{~dB}$ & $33,40 \mathrm{bB}$ \\
$30 \mu \mathrm{L}$ & $34,30 \mathrm{bB}$ & $59,15 \mathrm{dBC}$ & $25,00 \mathrm{aA}$ & $31,20 \mathrm{abB}$ & $48,20 \mathrm{cB}$ & $27,00 \mathrm{aAB}$ \\
$50 \mu \mathrm{L}$ & $23,20 \mathrm{abA}$ & $62,02 \mathrm{~dB}$ & $25,00 \mathrm{abcA}$ & $31,20 \mathrm{cB}$ & $18,67 \mathrm{aA}$ & $27,00 \mathrm{bcAB}$ \\
$\mathbf{1 0 0} \boldsymbol{\mu L}$ & $16,67 \mathrm{bcA}$ & $0,00 \mathrm{aA}$ & $25,00 \mathrm{dA}$ & $23,38 \mathrm{cdA}$ & $14,75 \mathrm{bA}$ & $25,98 \mathrm{dA}$ \\
\hline $\mathrm{F}($ Trat $)=$ & $67,03^{* *}$ & & & & &
\end{tabular}

Letras iguais minúscula na linha e maiscula na coluna não diferem entre si pelo teste de Tukey a $5 \%$ de probabilidade*, Teste F significativo ao nível de $5 \%{ }^{* *}$, C.V. Coeficiente de Variação. 
do controle. O óleo essencial de capim-limão nas concentrações de 10 a $100 \mu \mathrm{L}$ apresentaram efeito fungistático, diferindo do controle

\section{DISCUSSÃO}

A uma relação dose-dependente nos casos em que ocorre a inibição gradativa do fitopatógeno com o aumento das concentrações testadas (Machado et al., 2013).

Os resultados obtidos, para o óleo essencial de alecrim, foram similares aos encontrados por Soylu et al. (2010), em estudos realizados com óleo essencial de alecrim, no controle do fungo Botritis cinerea. Sousa Junior et al. (2009) obtiveram a inibição completa do crescimento micelial dos fungos Aspergillus niger, A. flavus e Fusarium sp. quando submetidos ao óleo essencial de alecrim na concentração de $25 \mu \mathrm{L}$ em condições laboratoriais.

Os óleos essenciais de capim-limão e canela apresentaram baixa eficiência no controle germinativo de conídios do fungo C. gloeporioides enquanto que os de alecrim e de menta se mostraram mais eficientes. Dados similares foram encontrados por Carnelossi et al. (2009) avaliando o óleo essencial de menta in vitro. Esses resultados contrariam os resultados obtidos por Lorenzetti et al. (2011) que determinou o efeito de diferentes óleos essenciais, dentre eles o capim-limão, canela, alecrim e menta sobre a germinação de conídios do fungo Botritis cinerea, relatando que os dois primeiros foram mais eficientes, chegando a inibir a germinação de isolados resistentes. Lorenzetti et al. (2012) ainda determinou o efeito do óleo essencial de menta, sobre a germinação de esporos do fungo Puccinia nakanishikii, obtendo resultados satisfatórios.

A elevada eficiência do óleo essencial de capim-limão também foi relatada por Santos et al. (2010) ao determinarem a fungitoxicidade in vitro dos óleos essenciais de capim-limão (Cymbopogon citratus), citronela (Cymbopogon nardus), em concentrações que variaram de 250 a 1250 ppm sobre o fungo Helminthosporium sp.

Embora os resultados obtidos para o capim-limão neste estudo sejam pouco satisfatórios, dentre os fatores que poderiam explicar a baixa eficiência desse óleo nesta pesquisa, pode-se citar a sua elevada capacidade volátil, o que contribui para eventuais perdas nas suas propriedades fungitóxicas.

Quando comparado aos melhores resultados obtidos neste estudo, pode-se dizer que o óleo essencial de árvore-chá apresentou uma eficiência mediana. No entanto, resultados similares a este foram relatados em outros estudos. Pereira et al. (2011) ao utilizarem o óleo essencial de árvore- chá no controle de Alternaria solani em tomateiro, observaram que essa substância inibiu parcialmente o crescimento micelial do fungo quando usadas em doses superiores a $750 \mu \mathrm{L}$.

O óleo essencial de canela apresentou baixo efeito sobre a germinação de conídios, in vitro e in vivo. Um dos fatores que poderia explicar a baixa eficiência apresentada pelo óleo essencial de canela neste trabalho seria a dosagem adotada. Jham et al. (2005) determinaram o efeito fungicida do óleo essencial de canela sobre os fungos Aspergillus flavus e $A$. niger, obtendo a inibição completa de crescimento a partir dos valores de $300 \mu \mathrm{L}$.

Os óleos essenciais possuem baixo risco ao ambiente, produtores e consumidores, além de não favorecerem o desenvolvimento de resistência do patógeno (Derbalah et al., 2012).

Os óleos essenciais de árvore-chá, menta, anis, alecrim e árvore-chá apresentam efeito fungitóxico e fungistático podendo ser utilizados no controle da antracnose.

\section{AGRADECIMENTOS}

Os autores agradecem o apoio financeiro da Capes e Fundect.

\section{REFERÊNCIA}

AKAMINE, E.K.; ARISUMI, T. Control of postharvest storage decay of fruits of papaya (Carica papaya L.) with special reference to the effect of hot water. Proceedings of the American Society for Horticultural Science, v.61, p.270-274, 1953.

CARNELOSSI, P.R. et al. Óleos essenciais no controle pós-colheita de Colletotrichum gloeosporioides em mamão. Revista Brasileira de Plantas Medicinais, v.11, n.04, p.399-406, 2009.

CERDEÑO, V.J.M. Hábitos de compra y consumo de frutas y hortalizas - Resultados del Observatório del Consumo y la Distribución Alimentaria. Revista Distribución y Consumo. n. 88, p.05-28, 2006.

DERBALAH, A.S. et al. Antifungal activity of some plant extracts against sugar beet damping-off caused by Sclerotium rolfsii. Annals of Microbiology. v.62, p.1021-1029, 2012.

FERREIRA, D.F. Sisvar: a computer statistical analysis system. Ciência e Agrotecnologia. v.35, n.06, p.10391042, 2011.

GUIRALDO, N. et al. Controle de doenças em sistema agroecológicos. Summa Phytopathologica. v.30, n.01, p.153-156, 2004.

GOMES, L.I.S. Métodos de inoculação de Colletotrichum gloeosporiodes e efeito de óleos essenciais no controle da antracnose em frutos de mamoeiro. 2008. 54p. Dissertação (Mestrado em Agronomia - Área de concentração Fitopatologia) Universidade Federal de Lavras.

GULAB N. J. et al. Identificação do principal composto

Rev. Bras. PI. Med., Campinas, v.18, n.1, supl. I, p.367-372, 2016. 
fungitóxico de óleo de casca de canela. Fitopatologia Brasileira. v.30, n.4, p.404-408, 2005.

LEITE, C.D. et al. Controle pós-colheita da podridãoamarga da maçã com o uso do óleo de Nim. Revista Brasileira de Agroecologia. v.4, n.2, p.1644-1648, 2009.

LEME, M.I.S. et al. Efeito in vitro de capim-limão no desenvolvimento micelial de Colletotrichum acutatum. Summa Phytopathologica. v.33, p.92, 2007.

LORENZETTI, E.R. et al. Bioatividade de óleos essenciais no controle de Botrytis cinerea isolado de morangueiro. Revista Brasileira de Plantas Medicinais. v.13, n.3, p.619-627, 2011.

LORENZETTI, E.R. et al. Controle da ferrugem das folhas do capim-limão [Cymbopogon citratus (DC.) Stapf] com produtos naturais. Revista Brasileiras de Plantas Medicinais. v.14, n.4, 2012.

MACHADO, R.M.A. et al. Avaliação de óleos essenciais sobre o crescimento in vitro do fungo colletotrichum gloeosporioides. Perspectivas online. v.08, n.03, p.64-75, 2013.

NERY-SILVA, F.A. et al. Metodologia de inoculação de fungos causadores da podridão peduncular em mamão. Ciência e Agrotecnologia. v.31, n.05, p.1374-1379, 2007.

NEHMI, I.M.D. et al. Anuário da Agricultura Brasileira. v.01, n.01. p.378-386. 2002. Disponível em:<<http://biblioteca.incaper.es.gov.br/busca?b=a $\mathrm{d} \& \mathrm{id}=5643 \&$ biblioteca $=$ vazio\&busca=autoria: $\% 22 \mathrm{I}$ NSTITUTO\%20FNP\%22\&qFacets=autoria:\%22INS TITUTO\%20FNP\%22\&sort=\&paginacao=t\&pagina Atual=2>>. Acesso em: 31 mar. 2016.

OLIVEIRA, R.A.G. et al. Estudo da interferência de óleos essenciais sobre a atividade de alguns antibióticos usados na clínica. Revista Brasileira de Farmacognosia. v.16 p. 77-82, 2006.

PEREIRA, R.B. et al. Potencial de óleos essenciais no controle da cercosporiose-do-cafeeiro. Ciência e Agrotecnologia. v.35, n. 01, p.115-123, 2011.

ROZWALKA, L.C. Controle alternativo da antracnose em frutos de goiabeira, em laboratório. 2003. 42p. Dissertação (Mestrado em Agronomia - Área de concentração em Produção Vegetal) - Universidade Federal do Paraná.

SANTOS, A.C.A. et al. Efeito fungicida dos óleos essenciais de Schinus molle L. e Schinus terebinthifolius Raddi, Anacardiaceae, do Rio Grande do Sul. Revista Brasileira de Farmacognosia. v.20, n. 02, p. 154159, 2010.

SILVA, D.MM.H.; BASTOS, C.N. Atividade antifúngica de óleos essenciais de espécies de Piper sobre crinipellis perniciosa, Phytophthora palmivora e Phytophthora capsici. Revista Fitopatologia Brasileira. v.32. p.143-145, 2007.

SOUSA JUNIOR, I.T.S. et al. Efeito fungitóxico de óleos essenciais sobre Colletotrichum gloeosporioides, isolado do maracujazeiro amarelo. Revista Biotemas. v.22, n.03, p. 77-83, 2009.

SOYLU, E.M. et al. In vitro and in vivo antifungal activities of the essential oils of various plants against tomato grey mould disease agent Botrytis cinerea, International Journal of Food Microbiology. v.143, p.183-9, 2010.

VENTURA, J.A.; COSTA, H.; Tatagiba, J.S. Manejo das doenças do mamoeiro. In: Martins, D.S.; Costa, A.F.S. A cultura do mamoeiro: tecnologias de produção. (Eds). Vitória: Editora Incaper, 2003. p. 229-308.

Rev. Bras. PI. Med., Campinas, v.18, n.1, supl. I, p.367-372, 2016. 